\title{
ERRATUM
}

\section{Erratum to: An RCT Investigating Patient-Driven Versus Physician-Driven Titration of BIAsp 30 in Patients with Type 2 Diabetes Uncontrolled Using NPH Insulin}

Abdelmjid Chraibi · Shoorook Al-Herz • Bich Dao Nguyen •

Djoko W. Soeatmadji · Anil Shinde · Balasubramanian Lakshmivenkataraman •

Samir H. Assaad-Khalil

Published online: June 20, 2017

(c) The Author(s) 2017. This article is an open access publication

Erratum to: Diabetes Ther

DOI 10.1007/s13300-017-0268-1

Published version of this article contains incorrect labeling in Fig. 3.

Label on the x-axis of Fig. 3b currently read: '90 min before breakfast', '90 min before lunch' and ' 90 min before dinner'.

These labels should read ' 90 min after breakfast', '90 min after lunch' and '90 min after dinner'.

The online version of the original article can be found under doi:10.1007/s13300-017-0268-1.

A. Chraibi $(\bowtie)$

Medical School of Agadir, Agadir, Morocco

e-mail: a.chraibi@uiz.ac.ma

A. Chraibi

Ibn Zohr University, Agadir, Morocco

S. Al-Herz

King Fahad National Guard Hospital, Riyadh,

Saudi Arabia

B. D. Nguyen

Tam Duc Heart Hospital, Ho Chi Minh City,

Vietnam
D. W. Soeatmadji

Saiful Anwar General Hospital Malang, Malang, Indonesia

A. Shinde

Novo Nordisk, Dubai Healthcare City, Dubai, UAE

B. Lakshmivenkataraman

Novo Nordisk, EPIP Phase I, Whitefield, Bangalore, India

S. H. Assaad-Khalil

Alexandria Faculty of Medicine, Alexandria, Egypt 

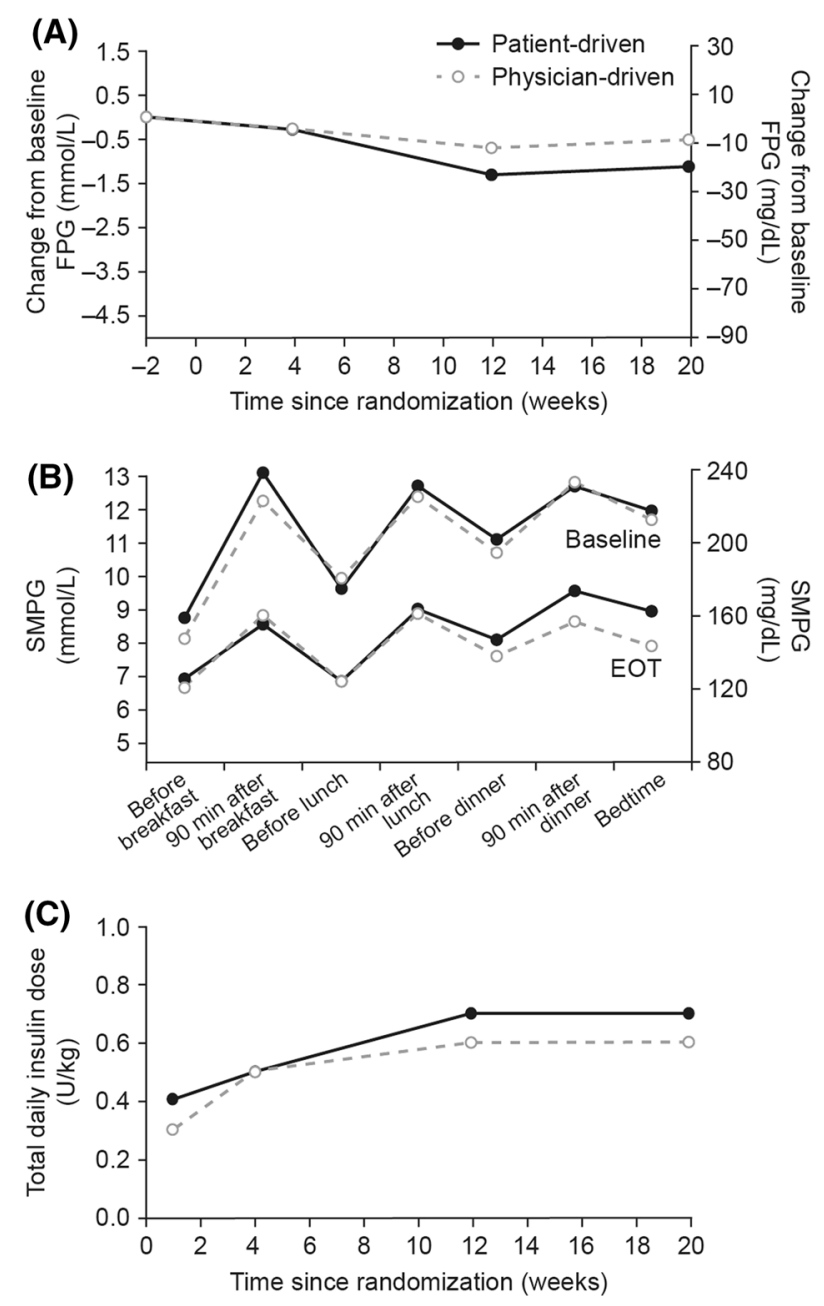

Fig. 3 a Mean change from baseline FPG (LOCF); b 7-point SMPG profiles from baseline and after 20 weeks of treatment (EOT); c total daily insulin dose. Data from

Open Access. This article is distributed under the terms of the Creative Commons Attribution-NonCommercial 4.0 International License (http://creativecommons.org/licenses/ by-nc/4.0/), which permits any noncommercial
FAS. EOT end of trial, $F P G$ fasting plasma glucose, $L O C F$ last observation carried forward, $S M P G$ self-measured plasma glucose

use, distribution, and reproduction in any medium, provided you give appropriate credit to the original author(s) and the source, provide a link to the Creative Commons license, and indicate if changes were made. 